\title{
"Seminário Marx", um capítulo brasileiro do marxismo ocidental?
}

\author{
Giovanna Henrique Marcelino*
}

\section{Resumo}

Nos anos 1960, o marxismo passou por um momento de renovação no Brasil, ao servir de base para um conjunto de teses dedicadas à interpretação da sociedade brasileira, entre as quais, aquelas que se desenvolveram a partir do que ficou conhecido como "Seminário Marx". Um pouco antes, esta tradição também havia passado por uma metamorfose na Europa, processo que resultou na consolidação de uma nova configuração intelectual - posteriormente denominada como Western Marxism composta por uma geração de teóricos marxistas que se giraram para o trabalho filosófico e perderam o vínculo com a prática política. Este trabalho visa realizar uma breve meditação acerca da relação de parentesco entre essas duas formas de marxismo: a que se desenvolveu em terras paulistanas e aquela gestada no continente europeu. Para tanto, o centro da análise será problematizar a noção de que o marxismo levado à cabo pelos membros do Seminário representaria "o capítulo brasileiro do marxismo ocidental", tal como sugerido por alguns autores. Com isso, espera-se refletir sobre a relação entre marxismo ocidental e o Brasil, e o paradoxo que percorre a história do marxismo brasileiro: o de precisar ser universal e particular ao mesmo tempo, tendo em vista o caráter internacional da tradição marxista, bem como a necessidade de adaptar suas formulações às realidades nacionais concretas.

Palavras-chave: Seminário Marx; marxismo brasileiro; marxismo ocidental; história do marxismo; Perry Anderson.

\section{Abstract}

In the 1960s, Marxism went through a period of renewal in Brazil, as it served as the basis for a set of theses dedicated to the interpretation of Brazilian society, including those that were developed during what became known as the "Marx Seminar". Shortly before, this tradition had also undergone into a metamorphosis in Europe, a process that resulted in the consolidation of a new intellectual configuration - later named Western Marxism - composed by a generation of Marxist theorists who turned to philosophical work and lost the link with political practice. This work aims to make a brief meditation on the relationship between these two forms of Marxism: the one developed in São Paulo lands and the one established on the European continent. In order to do so, the focus of the analysis will be to problematize the notion that the Marxism carried out by the members of the Seminar would represent "the Brazilian chapter of Western Marxism", as suggested by some authors. Thereby, it hopes to reflect on the relationship

\footnotetext{
* Doutoranda no Programa de Pós-Graduação em Sociologia da Faculdade de Filosofia, Letras e Ciências Humanas da Universidade de São Paulo (FFLCH/USP). E-mail: giovannahmarcelino@gmail.com.
} 


\begin{abstract}
between Western Marxism and Brazil and the paradox that runs through the history of Brazilian Marxism: that of having to be universal and particular at the same time, in view of the international character of the Marxist tradition, and the need to adapt its formulations to concrete national realities.

Key words: Marx Seminar; Brazilian Marxism; Western Marxism; history of Marxism; Perry Anderson.
\end{abstract}

\title{
O marxismo do Seminário
}

Como qualquer outro fenômeno político-cultural, o marxismo (seja como ciência ou prática) sempre esteve suscetível a mudanças históricas, a ponto de hoje duzentos anos após o nascimento de seu fundador - ser incontornável o reconhecimento do florescimento difuso de uma "centena de marxismos", cada qual específico e circunscrito a um determinado contexto. Como bem definiu Fredric Jameson, estes diversos marxismos, inerentes a diferentes tempos e lugares, são as formas locais "de uma ciência marxiana na história e em situações concretas, que estabelecem não só suas prioridades, mas também seus limites", cada um abrangendo "as determinações de classe e os horizontes cultural e nacional de seus proponentes" (Jameson, 1996, p. 19).

Não poderia ser diferente com o marxismo brasileiro, tendo em vista que sua constituição também foi fruto desta relação entre teoria e realidade, que no nosso caso se deu em dois atos principais: 1) o do "marxismo no Brasil", referente ao momento inicial de difusão e irradiação da tradição marxista no começo do século XX após o impacto da Revolução Russa, momento no qual predominou-se uma atitude "cosmopolita" pautada pela aplicação "chapada" de seus preceitos teóricos à realidade brasileira, haja visto, por exemplo, a transposição mecânica da ideia de uma sequência de modos de produção (escravismo-feudalismo-capitalismo) e a conceituação da sociedade colonial brasileira como semifeudal, levada à cabo pela linha oficial do Partido Comunista Brasileiro (PCB); e 2) do "marxismo brasileiro", com o esforço posterior de propriamente "nacionalizar" esta tradição, ou seja, de construir um marxismo próprio, a partir das contradições locais, capaz de compreender a sociedade brasileira em suas especificidades (Musse, 2015, p. 410).

Ou seja, até meados do século XX, o marxismo estava predominantemente confinado a um universo um tanto rígido e precário, sem vínculos aprofundados com a 
cultura do país (em parte devido às próprias dificuldades em torno do contexto de perseguição política àqueles que optavam por uma saída revolucionária e popular) (Schwarz, 1999a, 90). O amadurecimento de um marxismo efetivamente brasileiro empreitada iniciada por Caio Prado Jr. em sua interpretação sobre o "sentido da colonização" ${ }^{1}$ - teve os anos 1960 como ocasião primordial, momento de radicalização política e ideológica em que a versão exportada do "marxismo-leninismo" proveniente da União Soviética, até então preponderante nos círculos da esquerda brasileira, passou a lidar com a concorrência de outras vertentes, como o trotskismo, o maoísmo, o castrismo-guevarismo, assim como com a recepção dos chamados "marxistas ocidentais" (sobretudo Gramsci, Lukács e Althusser), algo que se combinou com uma maior adesão da intelectualidade ao marxismo, devido à sua disseminação nas universidades (Musse, 2015, p. 415).

A geração de estudiosos e acadêmicos agrupados em torno do chamado "Seminário Marx" talvez seja uma das expressões mais evidentes dessa associação entre um maior interesse universitário pelo marxismo e a busca por distanciamento em relação ao "marxismo oficial" (Schwarz, 1999a, p. 87). Grupo de estudos interdisciplinar formado entre os anos 1958 e 1964 por docentes e discentes da Faculdade de Filosofia, Ciências e Letras da Universidade de São Paulo (FFCL-USP) entre eles, jovens discípulos de Florestan Fernandes² -, o Seminário tinha como intuito primordial realizar uma leitura rigorosa e científica da obra máxima de Marx, O Capital, extraindo desta lições para pensar a realidade brasileira e encontrar uma solução para a modernidade capitalista no país, tendo em vista o ambiente social e político em que se dava tal empreitada: o de relativo otimismo do ciclo nacional-desenvolvimentista

\footnotetext{
${ }^{1}$ Em sua interpretação do passado colonial, Caio Prado Jr. rebate a tese defendida pelo PCB a respeito do caráter feudal da colonização brasileira mostrando como esta era, em realidade, um "empreendimento voltado para o mercado externo baseado na produção de gêneros tropicais em grandes unidades agrícolas trabalhadas pelo braço escravo" (Ricupero, 2000, p. 88). Nesse mesmo sentido, posteriormente os membros do "Seminário Marx", como Fernando Henrique Cardoso e Octavio lanni, questionam a redução do escravismo moderno a uma variante do modelo feudal europeu, atentando ao fato de que "o escravismo fora um componente decisivo do processo mundial de acumulação do capital” (Lahuerta, 2005, p. 173).

${ }^{2}$ Entre os membros que compuseram a formação original do Seminário estão: José Arthur Giannotti, Fernando Henrique Cardoso, Ruth Cardoso, Octavio lanni, Paul Singer, Fernando Novais, Bento Prado Júnior, Roberto Schwarz, Michael Löwy, Francisco Weffort, entre outros.
} 
nos anos 1950, em que se apostava na superação do atraso brasileiro por meio da industrialização ${ }^{3}$.

Como relata Paulo Arantes,

[...] porque não havia cursos especializados sobre Marx na Faculdade, alguns professores e alunos mais adiantados resolveram se reunir para ler $O$ Capital. Tratava-se de um encontro marcado sobretudo pelo propósito de rever integralmente as interpretações do país e do marxismo. [...] Sem favor algum, com o passar dos anos acabou surgindo daquele embrião meio improvisado, não os quadros de uma Revolução que não houve, mas o que ainda existe de menos dogmático, mais inventivo e original no ensaio marxista de interpretação da experiência brasileira (Arantes, 1994, p. 238).

Além de um empreendimento acadêmico que influiu sobre o marxismo local, pode-se dizer que a tarefa a qual o grupo se propunha guardava vínculos com o contexto internacional daquela época. Pois o mesmo "retorno à Marx" estava sendo realizado em diferentes países, sobretudo como resposta às frustrações desencadeadas pela divulgação das atrocidades realizadas pelo stalinismo em 1956, que alimentou um esforço de redefinição da esquerda para além do escopo dos Partidos Comunistas, indicando que uma revitalização política da tradição marxista deveria necessariamente passar por uma revitalização teórica de Marx ${ }^{4}$. Além do caso francês, pode-se destacar, por exemplo, o paralelo com o marxismo britânico que se desenvolveu sob o ambiente intelectual e político do pós-guerra em meio à formação da chamada New Left - esquerda independente que se pretendia terceira via em relação à socialdemocracia e ao stalinismo, representadas na época pelo Partido Trabalhista e o Partido Comunista inglês, as duas tradições dominantes da vida política britânica -, fomentando a formação de uma nova geração de intelectuais vinculados à universidade, com interesse renovado pela tradição marxista, como aquela que se agrupou em torno da revista New Left Review. Além disso, tal processo de

\footnotetext{
${ }^{3}$ Como relata Schwarz, o contexto nacional daquela época - e o ânimo progressista em torno da criação de novas indústrias, automóveis nacionais, da construção de Brasília, etc. - organizavam o imaginário social e o pensamento crítico dos membros do Seminário: "naqueles anos pareceu possível uma arrancada recuperadora, que tirasse a diferença que nos separava dos países adiantados" (Schwarz, 1999a, p. 88).

${ }^{4}$ Segundo Hobsbawm, "A partir de 1956, começa um período em que a maior parte dos marxistas foi obrigada a concluir que os regimes socialistas existentes - desde a URSS ou Cuba até o Vietnã - estavam distantes daquilo que se desejava fosse uma sociedade socialista ou uma sociedade no caminho da construção do socialismo" (Hobsbawm, 1989, p. 21).
} 
disseminação de círculos de leitura sobre $O$ capital nas universidades é narrado por David Harvey, que há anos leciona sobre o pensamento de Marx nos Estados Unidos. Para Harvey, no caso norte-americano, tal entusiasmo político e interesse pela obra provinha da necessidade de encontrar embasamento teórico e intelectual para compreender a ruptura política evidente que se vivia nos movimentos sociais a partir dos anos 1960 (Harvey, 2003, p. 259-263). É nesse sentido que, como aponta Roberto Schwarz, em sua tentativa própria de resgatar a vitalidade da obra de Marx, "à distância, o seminário paulistano sobre O capital fazia parte dessa contestação" mundial (Schwarz, 1999a, p. 88) ${ }^{5}$.

Junto a esse contexto, houve também a influência determinante da própria "cultura uspiana" daquele momento, pautada pela atmosfera acadêmica construída por Florestan Fernandes de consolidar uma sociologia estritamente científica e por sua agenda de pesquisa pautada em entender os "pressupostos sociais" do desenvolvimento econômico brasileiro, bem como pelo processo de inserção do marxismo no departamento de Filosofia da USP (Lahuerta, 2005, p. 157). Ou seja, o objetivo de ler $O$ capital se inseria num contexto científico mais imediato de um ambiente universitário que perseguia a consolidação de um padrão de pesquisa e de produção intelectual superior.

Dessa forma, a marca distintiva do grupo do Seminário foi justamente a de testar a superioridade científica da tradição marxista ${ }^{6}$, tanto perante o marxismo prevalecente no Brasil até então, quanto em relação a outras teorias sociais que não pareciam corresponder à necessidade de transformação pela qual passava a sociedade brasileira em seu processo de modernização e radicalização política. Tendo isso em vista, traçou-se um duplo objetivo: estabelecer o marxismo nos parâmetros da academia e redefini-lo nos termos da agenda local, entendendo que se tratava de uma

\footnotetext{
${ }^{5}$ Segundo Schwarz (Ibidem, p. 88), outro referencial internacional importante para o Seminário foi a Revolução Cubana de 1959, que também "desmentia o marxismo oficial, pois não foi feita por operários, não foi dirigida pelo Partido Comunista e não respeitou a sequência de etapas prevista na teoria". Para conferir como o mesmo evento teve impacto sobre o desenvolvimento do marxismo norte-americano, ver Jameson (1991).

${ }^{6}$ Como descreve Fernando Henrique Cardoso, "nos círculos acadêmicos mais conspícuos formou-se a conviç̧ão de que a interpretação dialética, por estar imediatamente vinculada a um ponto de vista filosófico e uma atitude definida diante dos problemas sociais, não é capaz de adequar-se aos cânones da explicação científica que impõem a ausência de juízos de valor nas análises sociológicas" (Cardoso,1977, p. 28).
} 
tradição que deveria ser repensada a partir do ponto de vista da periferia, já que os membros do Seminário estavam lidando com uma realidade que não foi descrita por Marx em $O$ capital $^{7}$. Grosso modo, as preocupações compartilhadas pelo grupo - que iriam se desdobrar, de diferentes maneiras, nas pesquisas individuais de cada membro - passavam pela elaboração de novas interpretações do Brasil (do momento colonial à inserção subordinada do país no sistema capitalista mundial contemporâneo) a partir de um marxismo renovado, independente de posições dogmáticas e "esquemas ortodoxos", sobretudo, legitimado no universo científico (Arantes, 1994, p. 238-239). Nas palavras de Schwarz,

[...] Os jovens professores tinham pela frente o trabalho da tese e o desafio de firmar o bom nome da dialética no terreno da ciência. De modo geral escolheram assunto brasileiro, alinhados com a opção pelos de baixo que era própria à escola, onde se desenvolviam pesquisas sobre o negro, o caipira, o imigrante, o folclore, a religião popular (Schwarz, 1999a, p. 93).

Nesse sentido, o caráter inédito do marxismo do Seminário residia na preocupação com o rigor científico e o refinamento analítico, algo que posteriormente produz desdobramentos não apenas teóricos como políticos ${ }^{8}$. O intuito primordial era o de realizar uma interpretação do Brasil com base na obra de Marx, abrindo-se um novo ciclo explicativo que seguia a geração ensaísta dos anos 1920-1930, só que agora alimentado pela tentativa de "modernizar" o marxismo, isto é, de tirar seus aspectos mais "arcaicos", por meio da especialização e profissionalismos próprios da universidade. Para tanto, a ênfase nas questões de método - como o exercício da dialética e da perspectiva da totalidade -, bem como a retomada de conceitos como os de ideologia, consciência, práxis, etc., tornaram-se cruciais, uma espécie de

\footnotetext{
${ }^{7}$ Como coloca Schwarz (1999a, p. 96), "faria parte de uma inspiração marxista consequente um certo deslocamento da própria problemática clássica do marxismo, obrigando a pensar a experiência histórica com a própria cabeça, sem sujeição às construções consagradas que nos serviam de modelo, incluídas aí as de Marx".

${ }^{8}$ Como aponta Lahuerta (2005 p. 176), "a leitura de Marx vai dar seus frutos mais significativos, inclusive com maiores consequências políticas, a partir de 1964, não só pelo abalo que a FFCL-USP sofreria com a intervenção militar, mas, principalmente, pela necessidade de acertar as contas com as interpretações vigentes até então e pelo imperativo de explicar o Golpe Militar e suas consequências para o País". Assim, apesar da escassa relação de muitos dos membros do Seminário com a militância e as organizações políticas, pode-se dizer que é equivocado encarar o grupo do Seminário como estritamente teórico, haja visto o posicionamento político implícito em relação ao nacionalismo teórico do PCB e ISEB, bem como a influência que tiveram na introdução de novos elementos para o pensamento político de esquerda e para se pensar saídas para o Brasil.
} 
pressuposto para apreender a complexidade do capitalismo dependente, em oposição tanto aos déficits das linhas interpretativas economicistas do marxismo ortodoxo, quanto das abordagens estrutural-funcionalistas predominantes na sociologia (que não consideravam a dinâmica histórica, a mudança e os antagonismos presentes na vida social).

Nessa "aclimatação filosófica do marxismo" se destaca, primeiramente, o papel desempenhado por José Arthur Giannotti, como documentado na publicação em 1960 do texto Notas para uma análise metodológica de O Capital, no qual explicita as coordenadas do trabalho coletivo de leitura desempenhado pelo grupo do Seminário, influenciado pela tradição francesa de realizar uma interpretação cerrada e metódica do texto, centrada no exame microscópico de suas estruturas argumentativas (Arantes, 1994, p. 254) ${ }^{9}$. Com isso, Giannotti consagra, inclusive, a filosofia como um ponto de vista obrigatório no projeto interdisciplinar do grupo, considerando que a leitura de $O$ Capital, além de base para interpretações sociais e econômicas, também era uma trincheira de controvérsia epistemológica. Nesse quesito, nota-se também a importância da digressão metodológica realizada por Fernando Henrique Cardoso, um ano depois, na introdução de sua tese Capitalismo e escravidão no Brasil meridional, atestando a cientificidade do método dialético e sua superioridade intelectual sobre o estrutural-funcionalismo (ponto polêmico pois esta era, então, a perspectiva epistemológica utilizada pelo seu orientador, Florestan Fernandes). Além disso, a partir da centralidade dada aos conceitos de totalidade, práxis, etc. - provenientes da recepção de autores como Lukács e Sartre -, Fernando Henrique propõe repensar o tema da relação entre capitalismo e escravidão no Brasil, buscando, com o apoio de uma base empírica, as determinações essenciais da relação dos agentes (senhores e escravos) com a totalidade concreta (a sociedade escravocrata rio-grandense) ${ }^{10}$. A tese

\footnotetext{
${ }^{9}$ Como relata Schwarz, Giannotti, “em sua estadia na França havia aprendido que os grandes textos se devem explicar com paciência, palavra por palavra, argumento por argumento, em vista de lhes entender a arquitetura" (Schwarz, op. cit., p. 91).

${ }^{10}$ Nas palavras de Fernando Henrique, "o livro visa analisar a totalidade social concreta que resultou da interação entre senhores e escravos na sociedade gaúcha" (Cardoso, 1977, p. 27). Com seu estudo, o autor desbancou o itinerário de etapas obrigatórias defendido pelo marxismo vulgar, ao identificar a relação não linear entre capitalismo e escravidão, mostrando como o capitalismo, apesar de em última instância ser incompatível com a escravidão, precisou dela em diversos momentos para desenvolver-se. A análise com foco na conjugação entre estrutura e ação também se faz presente em sua tese de livre
} 
de Fernando Novais (1983), outro membro do Seminário, também se destaca por utilizar a categoria de "totalidade complexa" como embasamento metodológico, desta vez para entender a crise do sistema colonial, e o Brasil como parte deste sistema, cujo eixo dinâmico estava na Europa.

Com efeito, pode-se dizer que as teses produzidas no âmbito do Seminário representaram tanto um forma de apropriação da obra de Marx na qual se destacam seus aspectos metodológicos (visível sobretudo na introdução da tese de Fernando Henrique, em que o marxismo se apresenta antes de mais nada como um "pressuposto metodológico" de sua pesquisa), quanto uma tentativa de alocar as peculiaridades sociológicas e políticas do Brasil à história do capitalismo (tal como presente no tema da escravidão e da crise do sistema colonial). Com isso, tais autores criaram o que Roberto Schwarz denominou de uma "nova intuição do Brasil", continuando o esforço aberto por Caio Prado Jr. de "nacionalização do marxismo" (Schwarz, 1999a, p. 93).

\section{Um capítulo brasileiro do marxismo ocidental?}

Em 1983, no jornal Folha de São Paulo, Paulo Arantes realiza uma resenha a respeito do livro de Ruy Fausto Marx, lógica e política, aparentemente um pretexto para associar o trabalho de "leitura filosófica" empenhado pelos membros do Seminário Marx com o chamado (por Perry Anderson) "marxismo ocidental" ${ }^{11}$. Para

docência Empresariado industrial e desenvolvimento econômico no Brasil, na qual, a partir de uma análise sociológica da industrialização e da mentalidade do agente desse processo, reforça a necessidade do desenvolvimento no país, porém criticando a aposta corrente naquele momento de que a burguesia nacional levaria à cabo esse processo - na medida em que esta não estaria realmente comprometida com a integração social, e sim satisfeita com sua condição de "sócio menor" do capitalismo global, nos deixando reféns a condição de "subcapitalismo". Com isso, Fernando Henrique denota o descompasso entre a ideia de desenvolvimento nos países do centro e da periferia, mostrando inclusive como as próprias categorias que nos serviam de modelo para entende-la (como burguesia nacional, classe trabalhadora, racionalidade econômica, etc.) também estavam deslocadas e deveriam ser reajustadas à luz da própria realidade brasileira, haja visto o caráter arcaico, irracional, clientelista das nossas relações sociais (ou seja, que em função das nossas condições objetivas, não desenvolvemos uma burguesia e proletariado moderno, no sentido explicitado pelos teóricos europeus).

${ }^{11}$ Como coloca também em outra entrevista: "seria do maior interesse um estudo comparado desses dois episódios do marxismo ocidental, o frankfurtiano e o brasileiro-uspiano, na falta de melhor denominação" (Arantes, 1996, p. 177). 
Arantes, o livro de Fausto seria um testemunho exemplar de como o marxismo desenvolvido pelos integrantes do Seminário consistiria o "capítulo brasileiro" desta linhagem que foi aberta por Lukács, após História e Consciência de Classe ${ }^{\mathbf{1 2}}$. Mais precisamente, ao propor uma reconstrução da dialética e uma redescoberta dos princípios lógicos do marxismo - até então "mascarada pelo aluvião das leituras ditas vulgares" -, o livro de Fausto (ao lado do trabalho levado à cabo por Giannotti) teria sido responsável por alimentar as bases filosóficas preparatórias do capítulo brasileiro do marxismo ocidental, cuja maturidade foi atingida com o trabalho realizado a partir do Seminário Marx (Arantes, 1983, p. 2).

Ou seja, Arantes argumenta em defesa de um "marxismo ocidental" à brasileira: o marxismo do Seminário seria senão uma variação nacional do processo de metamorfose que o marxismo vivenciou na Europa - sendo Lukács e Korsch, nesse caso, dois dos expoentes que prepararam o terreno filosófico, desenvolvido posteriormente pelo materialismo interdisciplinar dos frankfurtianos, que representaram a consolidação do marxismo ocidental enquanto linhagem no interior da história do marxismo no pós-guerra. Nesse sentido, o marxismo ocidental brasileiro integraria "um quadro mais amplo de um processo mundial desigualmente particularizado em suas manifestações locais que, por isso mesmo, formam um sistema" (Arantes, 1996, p. 178).

Para Arantes, apesar das diferenças de temporalidade e atmosfera histórica entre Brasil e Europa ${ }^{13}$, aquilo que colocaria o Seminário em linha de continuidade com o marxismo ocidental seria primordialmente a forma como ambos meditaram sobre o método, a partir de um acerto de contas com a desconfiguração promovida pelos "coágulos doutrinários" da tradição marxista. A preocupação filosófica dos membros do Seminário seria, então, a "versão caseira" da índole original europeia de

\footnotetext{
${ }^{12}$ Nas palavras de Arantes, "ao deslocar o centro de gravidade do pensamento de Marx das teses para o método, Lukács anunciava também um novo ciclo da cultura marxista, o do assim chamado "marxismo ocidental", do qual "História e Consciência de Classe" seria o primeiro clássico. Desde então o marxismo [...] tornou-se um interminável Discurso do Método, ocupando-se infatigavelmente com o do próprio Marx, fechando o circuito autoreferente da maré baixa" (Arantes, 1983, p. 3).

${ }^{13}$ Se na Europa, esse "recuo" para o método teria sido um resultado do refluxo da Revolução, no Brasil que vivia o ciclo do nacional-desenvolvimentismo - estaria relacionado ao próprio contexto uspiano e a tentativa de criar uma nova cultura de estudos acadêmicos no departamento de filosofia da USP. Cf. Arantes (1994).
} 
restaurar a verdadeira ortodoxia do marxismo: a dialética (Lukács, 2012, p. 64). E o trabalho de Ruy Fausto e Giannotti representariam esse "traço mais saliente" do marxismo ocidental, o "metodologismo obsessivo", cujo principal traço, para Arantes, seria a ausência de lastro social: "a análise da armação conceitual acabou se sobrepondo à crítica das formas reais da mencionada "objetividade social". No que resultou um marxismo mais afiado na leitura de $O$ Capital do que na crítica do capitalismo" (Arantes, 1994, p. 292).

A questão, no entanto, é se, ao se amparar apenas na questão de método presente no marxismo filosófico paulista para sustentar seu argumento, Paulo Arantes não estaria na verdade utilizando de forma uma tanto flexível, ou restrita, a noção de "marxismo ocidental".

Na difundida definição de Perry Anderson - que se destacou diante de outros sentidos atribuídos ao termo ${ }^{14}$ por seu esforço de compreender a noção em termos históricos, em sintonia com as tentativas inglesas de realizar uma "história do marxismo", como a de Eric Hobsbawm - "marxismo ocidental" é utilizado especificamente para designar uma mutação sofrida no marxismo europeu a partir do período entreguerras.

Em seu livro Considerações sobre o marxismo ocidental, Anderson organiza e situa o desenvolvimento histórico do marxismo na forma de uma sucessão de gerações, que vai desde os fundadores do materialismo histórico (Marx e Engels) até a o advento e consolidação do marxismo ocidental como uma tradição comum a um conjunto de intelectuais marcados pelo signo da "derrota política", isto é, pelo fracasso das revoluções proletárias nos países centrais da Europa depois da Primeira Guerra Mundial, desenvolvendo a teoria marxista sob uma conjuntura bastante controversa, marcada pelo fascismo, stalinismo e o reformismo ${ }^{15}$.

\footnotetext{
${ }^{14}$ Não se trata, entretanto, da única definição existente. Como destaca Ricardo Musse, o termo marxismo ocidental "nunca foi passível de uma determinação unívoca", tendo em vista que, desde a primeira vez em que foi posto em circulação, cada autor que o utiliza "compõe à sua maneira as características principais do objeto, ora alterando o conjunto de componentes, ora a abrangência temporal ou geográfica do conceito" (Musse, 2012, p. 131). Cf. Korsch (2008) e Merleau-Ponty (2006).

15 "A característica oculta do marxismo ocidental como um todo, portanto, é ser um produto da derrota" (Anderson, 2004, p. 62).
} 
$\mathrm{Na}$ listagem dos nomes que compõe este esquema geracional apresentado por Anderson, a variante do marxismo ocidental seria formada por dois grupos principais: aquele que se formou politicamente durante a Primeira Guerra e a Revolução Russa, composto por Lukács, Korsch, Gramsci, Benjamin e Marcuse; e aquele que se estabeleceu posteriormente, influenciado já pelo fascismo e pela Segunda Guerra Mundial, composto por Horkheimer, Della Volpe, Lefebvre, Adorno, Sartre, Goldmann, Althusser e Coletti. Esta seria, portanto, a quarta geração do desenvolvimento histórico do marxismo, sucedendo sua tradição clássica, representada pela geração dos fundadores do materialismo histórico, Marx e Engels (primeira geração), de Labriola, Mehring, Kautsky e Plekanov (segunda geração, vinculada a vida política dos partidos operários e que deu continuação ao trabalho de Engels de sistematização e continuidade dos temas elencados por Marx em sua obra), e a de Lenin, Rosa Luxemburgo, Hilferding, Trotsky, Buhkarin (terceira geração, formada por quadros teóricos do capitalismo e estrategistas da organização partidária), nas quais ainda se sustentava um trabalho teórico organicamente comprometido com projetos políticos de transformação da sociedade.

Como metodologia de análise, Anderson se utiliza de duas operações principais: 1) a determinação de características formais gerais comuns ao conjunto dos intelectuais europeus agrupados sobre o termo "marxismo ocidental"; 2) o delineamento da especificidade desta linhagem, a partir de um balanço histórico que a compara com as gerações anteriores desta tradição (Musse, 2012). A partir deste balanço, o autor então atesta que a tradição marxista no período entreguerras passou por uma mudança em sua própria autocompreensão enquanto corpus teórico-prático, o que levou a uma série de mudanças em relação ao marxismo clássico: em linhas gerais, o centro gravitacional da produção marxista se deslocou da crítica da economia política para os estudos de filosofia, das questões de método para as investigações sobre a cultura, de forma a fomentar inovações temáticas, por um lado, e uma elaboração teórica desvinculada da ação política, por outro. Com isso, houve também uma mudança de terreno institucional: o "lugar" do marxismo passou a ser menos identificado com o partido e com as organizações socialistas, e mais com o ambiente acadêmico; a prática foi em certo sentido substituída pela "prática teórica"; e os 
intelectuais - um estrato social que se tornou mais amplo e importante no pós-guerra com a expansão do número de instituições de ensino superior - passaram a ter mais influência no desenvolvimento do marxismo (Anderson, 2004, p. 151-152). Ou seja, houve, segundo Anderson, um estreitamento do campo de ação desta tradição ao terreno das universidades, bem como a perda de seu discurso estratégico, devido ao ofuscamento da relação tradicional entre intelectuais e organizações políticas e à integração do marxismo à vida acadêmica, que gerou o declínio da figura do dirigente e intelectual de partido e a proliferação da figura do "teórico", bem como a aproximação com correntes não marxistas do pensamento contemporâneo e a predominância de um certo "pessimismo" como marca dos escritos de seus proponentes (Anderson, 2004, p. 108).

Para Perry Anderson, portanto, o marxismo teria passado por uma "academização", efetuando um "giro" para a filosofia -traço retomado por Paulo Arantes -, em parte devido à própria mudança drástica de conjuntura após a Revolução Russa, por outro em decorrência da descoberta tardia de um dos mais importantes trabalhos do jovem Marx, os Manuscritos econômico-filosóficos de $1844^{16}$. Entretanto, Anderson claramente se utiliza de uma série de outros critérios para além da predominância do trabalho epistemológico em sua caracterização do marxismo ocidental, como o temático (ênfase na cultura, estética, etc.) e político (expresso sobretudo no que ele chama de "divórcio entre teoria e prática" ${ }^{17}$, como se os marxistas ocidentais tivessem levado adiante apenas metade do programa traçado por

\footnotetext{
${ }^{16}$ De acordo com Anderson (Ibidem, p. 72), portanto, a trajetória do desenvolvimento do marxismo foi paradoxalmente invertida pelo marxismo ocidental: enquanto Marx moveu-se da filosofia aos estudos sobre a economia política, os marxistas ocidentais fizeram o caminho contrário.

${ }^{17}$ Anderson delimita a questão da separação entre teoria e prática como a principal diferença entre o marxismo clássico e o marxismo ocidental: "A unidade orgânica entre teoria e prática realizada pelos teóricos da geração clássica de marxistas [...] seria progressivamente desfeita entre 1918 e 1968 " (Ibidem, p. 50). Lukács, Gramsci e Korsch, que compõem o período de transição, foram ainda líderes de partidos revolucionários e de levantes de massas. No entanto, a morte de Gramsci na Itália e o exílio de Korsch nos EUA e de Lukács na URSS marcam o fim da fase em que o marxismo ocidental esteve próximo das massas. A partir de então, a própria trajetória do Instituto de Pesquisas Sociais, com sua transferência para os EUA e posteriormente para a Alemanha Ocidental, demonstra os rumos que seguiram o marxismo ocidental. Nos partidos comunistas, o espaço para a atividade intelectual marxista reduzia-se drasticamente, embora esses partidos representassem muitas vezes o único elo possível com a política socialista organizada. Por isso, aos teóricos restava uma das três opções: incorporar-se ao partido comunista e aceitar sua disciplina; não estar no partido e ser um intelectual independente; ou evitar qualquer filiação e qualquer referência à política.
} 
Lukács, constituindo-se como uma teoria crítica e dialética, mas amputada da sua resolução prática, a revolução proletária). ${ }^{18}$ Além disso, contrariando Arantes, chega a dizer que se trata de uma linhagem que carece de qualquer tipo de internacionalismo: “Não há no marxismo ocidental nenhum caso de intercâmbio ou conflito teórico total entre pensadores ou escolas e menos ainda de uma perspectiva geral do âmbito internacional da sua tradição" (Anderson, 2004, p. 89).

Ou seja, será que a noção de "marxismo ocidental" é mesmo passível de ser aplicada para pensar o caso brasileiro ${ }^{19}$ Se seguirmos o esquema de análise proposto por Anderson, é visível que a proximidade entre o marxismo uspiano e a tradição ocidental é relativa. Por um lado, nota-se as afinidades já citadas: a preocupação com o método e com os aspectos da superestrutura, a tentativa de uma apropriação nãodogmática do marxismo, a relação com o ambiente acadêmico, o caráter interdisciplinar, o diálogo com outras correntes de pensamento, etc. Mas se analisarmos o critério do contexto histórico marcado pela "derrota política", percebese um descompasso imediato: na caracterização de Anderson, o impacto do fascismo, stalinismo e do reformismo foram cruciais para o surgimento e consolidação do marxismo ocidental na Europa e de seu pessimismo latente; enquanto no Brasil, o cenário era o oposto: o de radicalização política e de otimismo nacionaldesenvolvimentista, pautado pela esperança de que poderia haver uma saída para o "atraso" brasileiro por meio da industrialização.

No caso brasileiro, a atmosfera de derrota que originalmente influenciou o advento do marxismo ocidental europeu viria à tona apenas com a ditadura militar

\footnotetext{
18 "O método como impotência, a arte como consolação, o pessimismo como imobilidade" (Ibidem, p. 113).

${ }^{19}$ Isso sem levar em conta que o próprio Perry Anderson faz uma revisão das suas definições expostas em Considerações sobre o marxismo ocidental, reconhecendo o caráter "ativista" de seu trabalho, sobretudo ao ter julgado politicamente o "giro filosófico" do marxismo ocidental. Pois à época, Anderson, que se reconhecia militante trotskista, apostava numa reunificação entre teoria e prática após o ascenso dos movimentos estudantil e operário em Maio de 1968, algo que acabou não acontecendo e o colocou em situação de revisão de suas próprias teses, como presente no Posfácio de Considerações sobre o marxismo ocidental e no seu livro Nas trilhas do materialismo histórico. Como aponta Musse, a postura inicial de Anderson desconsiderava, inclusive, temas políticos que estão no cerne das teorias dos marxistas ocidentais, como "a crítica a concepção de partido e à estratégia da Segunda e da Terceira Internacionais, o repúdio ao socialismo realmente existente, o refluxo do processo revolucionário, a integração do proletariado, enfim, a própria crise do marxismo" (Musse, 2012, p. 121-122).
} 
(com maior repressão, exílio, clandestinidade) e com o fim do ciclo nacionaldesenvolvimentista (que era o que permitia o pensamento crítico ter um horizonte otimista), eventos que tiveram impacto importante na intelectualidade de esquerda e suas interpretações sobre o Brasil, visível sobretudo nos desdobramentos subsequentes da linhagem intelectual proveniente do Seminário, como a teoria da dependência, o debate em torno da democracia e da sociedade civil nos anos 1970 e 1980 e a crítica ao avanço do neoliberalismo nos anos 1990 (avanço que teve contraditoriamente como um de seus protagonistas um dos expoentes do Seminário Marx ao se tornar presidente da República). Ou seja, pode-se dizer que a intelectualidade brasileira teve um pessimismo tardio - desabrochado sobretudo na mudança de atmosfera entre os anos 1980 e 1990, após a dissipação das esperanças do pós-redemocratização, em torno dos "novos movimentos sociais", das câmaras setoriais de base, etc. -, sintetizado em formulações como a de "colapso da modernização" brasileira (Roberto Schwarz), "anulação da política" (Chico de Oliveira) e "brasilianização do mundo" (Paulo Arantes), todas de certa forma assinalando como estava na ordem do dia a necessidade de uma virada negativa no pensamento crítico brasileiro (Schwarz, 1999b).

Em realidade, como aponta Roberto Schwarz, em grande medida o otimismo e a aposta ideológica na industrialização e modernização do capitalismo brasileiro pelos marxistas do Seminário até a ditadura militar seria inclusive resultado do "descaso" que estes tiveram em relação à análise do fetichismo da mercadoria e à crítica das formas de alienação presentes nos trabalhos dos frankfurtianos, ou seja, decorreria da cegueira em relação ao "avesso" da industrialização, ou seja, seu lado degradante ${ }^{20}$. Em suas palavras,

[...] Não houve muito interesse pela crítica de Marx ao fetichismo da mercadoria. Como correspondia àqueles anos de desenvolvimentismo, o foco estava nos impasses da industrialização brasileira, que podiam até empurrar na direção de uma ruptura socialista, mas não levavam à crítica

\footnotetext{
${ }^{20}$ Nesse sentido, também parece inadequada a aplicação de outra definição de "marxismo ocidental" ao marxismo do Seminário, tal como proposta por Goran Therborn (2012) - o marxismo ocidental como a tendência mais consoante com o caráter contraditório e negativo da modernidade. Para Therborn, o traço distintivo do marxismo ocidental seria o fato deste ser fiel a um dos traços mais fortes da obra de Marx, a "dialética da modernidade", capaz de combinar os aspectos positivos e negativos do desenvolvimento capitalista.
} 
aprofundada da sociedade que o capitalismo criou e de que aqueles impasses formam parte. [...] A parte da lógica da mercadoria na própria produção e normalização da barbárie pouco entrava em linha de conta e ficou como o bloco menos oportuno da obra de Marx. Pelas mesmas razões faltou ao seminário compreensão para a importância dos frankfurtianos, cujo marxismo sombrio, mais impregnado de realidade que os demais, havia assimilado e articulado uma apreciação plenas das experiências do nazismo, do comunismo stalinista e do american way of life, encarado sem complacências. Daí também uma possível inocência do grupo em relação ao lado degradante da mercantilização e industrialização da cultura, considerados sem maiores restrições. E daí, finalmente, uma certa indiferença em relação ao valor de conhecimento da arte moderna, incluída a brasileira, a cuja visão negativa e problematizadora do mundo atual não se atribuía importância (Schwarz, 1999a, p. 103-104).

Ao defender que o marxismo do Seminário deveria ter sido "mais ocidental", Schwarz curiosamente guarda uma postura similar a de Perry Anderson nos anos 1960, quando assume a direção da revista New Left Review (ou seja, antes de escrever Considerações sobre o marxismo ocidental, obra que notadamente atesta uma inflexão do autor com esta tradição). Também interessado numa renovação teórica do marxismo britânico, Anderson defende à época a introdução dos teóricos do marxismo ocidental (como Lukács, Korsch, Gramsci, Adorno, Horkheimer, Marcuse, Della Volpe, Colletti, Sartre e Althusser) para o enriquecimento do marxismo local. Sob a direção de Anderson, a New Left Review passou então a introduzir a obra destes autores, tornando-se uma das principais fontes de contato dos britânicos com o marxismo europeu no pós-guerra, por meio de traduções e publicações regulares nas edições da revista.

Outro desencontro - assinalado também por Schwarz - que dificulta a aplicação imediata da definição de Anderson para se pensar o Seminário Marx se relaciona ao tema nacional: de forma geral, os marxistas ocidentais não estavam necessariamente preocupados ou empenhados em encontrar uma "saída nacional" específica para o cenário dos países capitalistas europeus, ao contrário dos brasileiros, marcados pela sina de buscar a superação de sua condição colonial-periférica de subdesenvolvimento, algo que se traduziu nos próprios temas e objetos de pesquisa - os impasses do desenvolvimentismo e a tematização do atraso brasileiro, a relação entre capitalismo e escravidão, a crise do antigo sistema colonial, a "comédia ideológica" brasileira, etc. (Arantes, 1996, p. 176-177). Isso explica também o quão relativo é o diagnóstico da 
dissociação entre teoria e prática no caso brasileiro, ou que o grupo do Seminário tinha um caráter apenas teórico, haja visto a inserção do marxismo uspiano nos temas políticos do país, na tentativa de encontrar alguma solução para a modernidade capitalista brasileira.

Outro autor que, apesar de ter um ponto de partida diferente de Arantes, também defende a utilização do conceito para se pensar o desenvolvimento do marxismo no Brasil é Emir Sader - membro da "segunda geração" do Seminário Marx, como ele mesmo se autodenomina ${ }^{21}$. Para Sader, os fatores similares entre marxismo ocidental e marxismo brasileiro são suficientes para a aplicação da análise de Anderson ao nosso contexto, a começar pelo critério geracional: para ele, é possível dizer que a primeira fase do marxismo no Brasil (sua "geração clássica") seria composta por intelectuais marxistas vinculados ao PCB (sendo Caio Prado Jr. o primeiro caso de cisão após o processo de "bolchevização" dos Partidos Comunistas que levou ao estreitamento das condições de debate e de elaboração teórica); e a segunda geração de intelectuais nos anos 1960, no qual se inicia a introdução e influência das ideias de autores como Lukács, Gramsci e Althusser (por Carlos Nelson Coutinho, Leandro Konder, etc.), e um maior peso dos marxistas universitários que possuíam um interesse renovado pela obra de Marx, como o grupo do Seminário.

Sader segue à risca as fórmulas de Anderson a ponto de defender que a partir dos anos 1970, o marxismo ocidental se consolida como a "tendência predominante do marxismo brasileiro", tendo em vista o peso de análises culturais e estéticas, das questões de método, exegese dos textos de Marx em detrimento das análises econômicas, históricas e políticas (sendo Roberto Schwarz uma das expressões mais significativas desta tendência), e do desaparecimento do intelectual ligado à vida pública, processo relacionado à profissionalização e "academização" do marxismo, cuja

\footnotetext{
21 “[...] Não posso falar senão como participante da segunda geração daquela que teve a participação do próprio Roberto, de Ruy Fausto, Emília Viotti, Marilena Chauí, Sérgio Ferro, João Quartim, Francisco Weffort, Lourdes Sola, Cláudio Volga Albertina Costa, Paulo Sandroni e Beth Milan, entre outros. Sucedendo à primeira, tinha um esquema parecido - leitura de cerca de 50 páginas a cada duas semanas, valendo-se da diversidade de formação dos participantes num marco de homogeneidade geral em torno do marxismo" (Sader, 2005, p. 172). Além disso, Sader recebeu influência direta de Anderson ao fazer parte da Teoria e Prática, revista dirigida pela segunda geração do Seminário que seguia o modelo da New Left Review, pretendendo-se o desdobramento mais político do marxismo uspiano. Cf. Sader (2004).
} 
linguagem se tornou "inacessível" ao grande público (Sader, 2004, p. 12; 2005, p. 161162). $E$, quanto a isso, parece ter o mesmo julgamento político de Anderson: trata-se de uma forma de marxismo "sem reflexões estratégicas, sem abordagens globais sobre o capitalismo, e, portanto, sem força para recriar um pensamento anti-capitalista" (Sader, 2005, p. 176-177). Por isso, defende que não foi a leitura dos frankfurtianos que faltou para os membros do Seminário - como sugere Schwarz - mas as “mediações históricas e políticas concretas presentes nos textos de Gramsci, nas análises históricas de Marx, nas obras de Lenin e de Trotsky", seguindo a sugestão de que a renovação do marxismo e sua reconexão com a prática deveria passar necessariamente pela retomada do espírito da tradição clássica (Ibidem, p. 176).

Ao transpor o diagnóstico da dissociação entre teoria e prática do marxismo ocidental para o caso brasileiro, Sader parece desconsiderar o fato de um dos membros do Seminário ter se tornado presidente do país, além da relação de outra parte do grupo com a fundação do Partido dos Trabalhadores (PT). No plano da análise, parece também ignorar outros desdobramentos do marxismo do Seminário, como a obra de Francisco de Oliveira, que, a partir de um acerto de contas com as teorias do desenvolvimento (tanto da CEPAL como do CEBRAP), propôs uma análise das forças sociais internas que possibilitaram o desenvolvimento do capitalismo no Brasil, promovendo assim uma análise abrangente, econômica e política da situação nacional até os anos do governo Lula (Oliveira, 2003; Querido, 2018).

\section{Roberto Schwarz, um marxista ocidental-brasileiro}

Apesar das limitações de se aplicar em bloco a definição proposta por Anderson ao marxismo brasileiro, vale destacar a relação específica de um dos proponentes do grupo do Seminário com a tradição ocidental: Roberto Schwarz. Como descreve Arantes, Schwarz é um "frankfurtiano de carteirinha", o que facilita tal associação (Arantes, 1996, p. 183). Já Francisco Alambert (1998, p. 229) chega a dizer que o autor pode ser considerado "o mais ilustre representante do marxismo ocidental entre nós", guardando inclusive parentesco com esta linhagem devido a sua situação de origem: judeu, nascido em Viena, veio ao Brasil impelido pela Segunda Guerra Mundial e o 
antissemitismo nazista, vivenciando uma atmosfera comum à dos frankfurtianos - algo que sem dúvida influenciou seu pensamento e explica formulações marcantes em sua obra como a de desajuste entre ideias e lugar.

A especificidade de Schwarz em relação aos outros autores provenientes do Seminário está vinculada ao fato dele ter trilhado de maneira mais contundente um dos caminhos inovadores do marxismo ocidental: a crítica ao capitalismo, cujo ponto de partida são as superestruturas. Seguindo o legado de Adorno, Schwarz se preocupou com a vida ideológica e pensou o Brasil a partir do exame de suas manifestações culturais, realizando o mesmo procedimento dialético defendido por Jameson - outro herdeiro da tradição ocidental, nos Estados Unidos - de realizar um "pensamento ao quadrado, um pensamento sobre o próprio pensar" (Jameson, 1985, p. 41-42). Assim, defendeu que a compreensão das especificidades do funcionamento ideológico no Brasil revelam aspectos essenciais da realidade brasileira, seguindo o princípio adorniano de que a matéria de qualquer fenômeno cultural "é historicamente formada, e registra de algum modo o processo social a que deve a sua existência" (Schwarz, 2014a, p. 64) ${ }^{22}$. Ao examinar o liberalismo do século XIX, por exemplo, o autor observa que, o que era originalmente uma ideologia na Europa, se converteu no Brasil em uma "ideologia de segundo grau" ${ }^{23}$, ou ainda, uma "ideia fora do lugar", que revelaria, por sua vez, um mecanismo social:

[...] procurei ver na gravitação das ideias um movimento que nos singulariza. Partimos da observação comum, quase uma sensação, de que no Brasil as ideias estavam fora de centro, em relação ao seu uso europeu. E apresentamos uma explicação histórica para esse deslocamento, que envolvia as relações de produção e parasitismo no país, a nossa dependência econômica e seu par, a hegemonia intelectual da Europa, revolucionada pelo Capital. Em suma, para analisar uma originalidade nacional, sensível no dia a dia, fomos levados a refletir sobre o processo da

\footnotetext{
${ }^{22}$ Tal procedimento é novamente semelhante ao de Jameson (1992), que parte também de Adorno para defender a ideia de que todo produto cultural contém um inconsciente político; ou seja, inconscientemente, todo artefato cultural contém em si uma historiografia de sua própria época, na maioria das vezes de uma forma reprimida, sendo assim a tarefa do crítico conseguir interpretá-la e decifrá-la. Desse modo, o autor se preocupa em analisar as produções culturais como meio de mapear os traços sociais e históricos que organizam a sociedade e, assim, "periodizar" o capitalismo.

${ }^{23}$ Como sintetiza Ricupero (2008, p. 59-60), "o liberalismo na Europa corresponderia às aparências, num contexto onde prevalecia o trabalho livre e a igualdade perante a lei. Já no Brasil, onde o trabalho escravo era dominante e, consequentemente, relações materiais de força eram normais, a exploração se revelaria sem subterfúgios. Mas aqueles que não eram escravos se relacionariam, para além da força, por meio do favor e, dessa maneira, afirmariam sua condição de homens livres".
} 
colonização em seu conjunto, que é internacional. O tique-taque das conversões e reconversões de liberalismo e favor é o efeito local e opaco de um mecanismo planetário (Schwarz, 2014a, p. 62-63).

Schwarz, portanto, revela o que seria a "comédia" que marca a vida ideológica brasileira - a do desajuste, da inadequação entre ideias e contexto social, ou ainda, a do "sentimento de contradição entre a realidade nacional e o prestígio ideológico dos países que nos servem de modelo", que faz com que brasileiros tenham "constantemente a experiência do caráter postiço, inautêntico, imitado da vida cultural" (Schwarz, 2014b, p. 81-82) ${ }^{24}$. Para Schwarz, trata-se, entretanto, de um processo inevitável: apesar de nossas condições sociais terem geralmente pouco em comum com as que produziram originalmente as referências ideológicas europeias, o Brasil, enquanto país periférico que almeja participar da modernidade e ter o mesmo padrão de desenvolvimento dos países do centro, a todo instante toma emprestados seus modelos culturais, políticos, jurídicos, etc. (Ibidem, p. 95). O problema, portanto, não é a cópia em si, mas a forma como ela se dá, já que as categorias europeias provêm de um espaço "diverso mas não alheio" à realidade brasileira, que está igualmente inserida na dinâmica internacional do capital (Ibidem, p. 95-96).

Nesse sentido, parece mais correto enxergar a singularidade de Schwarz não pelo viés de ser um "representante brasileiro do marxismo ocidental", mas por seu acerto em ter lidado de maneira produtiva com a inadequação entre essa tradição proveniente do centro e a realidade brasileira. Pois, em última instância, o marxismo ocidental também não escapava da condição de ser mais uma "ideia fora do lugar", passível de ser ajustada ao ser repensada à luz do nosso contexto - a exemplo do debate que o autor realiza sobre o realismo de Machado de Assis. Schwarz, portanto, lidou com o problema de como se realiza esse deslocamento de ideias, a transposição da teoria marxista para o nosso contexto, já que é comprovado que sua aplicação direta necessariamente cai em equívocos, ao mesmo tempo que o processo de imitação é inevitável. A saída apresentada foi a de reconhecer a relação simultânea de discrepância e complementaridade entre as ideias de centro e a realidade da periferia, respeitando a dialética entre particular e universal.

\footnotetext{
${ }^{24}$ "Ao longo de sua reprodução social, incensavelmente o Brasil põe e repõe ideias europeias, sempre em sentido impróprio" (Schwarz, 2014a, p. 62).
} 


\section{Considerações finais}

Como vimos, a pergunta sobre a existência de um "capítulo brasileiro" na história do marxismo ocidental está inserida no âmbito de um problema mais amplo que percorre toda a história do pensamento marxista no Brasil: o de reconhecer o caráter internacional dessa tradição, bem como a necessidade de adaptar suas formulações à nossa realidade nacional concreta. Ou seja, pressupõe a forma como encaramos a universalidade do marxismo, diante de nossa condição - compartilhada com outros países da América Latina - de consumidores do "que os outros criaram

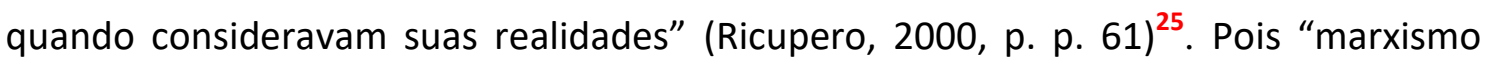
ocidental" nada mais é do que mais uma categoria originalmente proveniente do pensamento europeu, usada, inclusive, para nomear não uma linhagem que se designou como tal, mas para caracterizar a posteriori um momento específico e localizado da história da tradição marxista (Therborn, 2012, p. 77).

Parece correto afirmar que a recepção que este conceito teve no Brasil - por intermédio, por exemplo, de figuras como Paulo Arantes, Roberto Schwarz, Emir Sader - esteve relacionada com a tentativa de dar nome a um momento em que os marxistas brasileiros, em consonância ou mesmo influenciados pelos pensadores europeus, buscavam realizar uma apropriação não-dogmática desta tradição, empreitada que teve como tópico comum a discussão sobre a real "ortodoxia" do marxismo - o método dialético. Porém, pode-se dizer que, no caso brasileiro, o que estava realmente em jogo não era necessariamente a pretensão de ser uma versão brasileira do marxismo desenvolvido no continente europeu, mas sim a busca por um marxismo efetivamente brasileiro, com cara e identidade própria, algo que não estava em questão para o universalismo dos marxistas ocidentais. Além disso, o marxismo

\footnotetext{
${ }^{25}$ Este é o paradoxo do marxismo brasileiro: para se realizar, deve ser universal e particular ao mesmo tempo. Como diz Leandro Konder (2010), se renunciar à universalidade - isto é, a filosofia de compreender criticamente a sociedade capitalista e a si mesmo - "estará renunciando tanto a ser marxismo como a ser brasileiro". Ao mesmo tempo, para ser concreto, deve reconhecer as particularidades e as conotações singulares do capitalismo no Brasil, concebendo-se, portanto, enquanto uma intervenção crítica e transformadora tanto na história do marxismo no mundo, como na cultura brasileira.
} 
ocidental foi antes de mais nada "uma ideia fora do lugar" no Brasil desenvolvimentista dos anos 1950-1960, assentando-se e aclimatando-se ao nosso contexto realmente a partir do trabalho crítico realizado por membros do Seminário, sobretudo, com a abertura da conjuntura dos anos 1990, na qual se tornou mais atualizada a necessidade da dialética negativa que os frankfurtianos, por exemplo, ofereciam. Ou ainda, se houve um "marxismo ocidental à brasileira" no período do Seminário, ele contraditoriamente enfatizou os aspectos positivos da industrialização e, portanto, não foi tão ocidental quanto deveria, conforme sugere o balanço de Schwarz.

Por isso, o aspecto que talvez melhor traduz as semelhanças dessas duas formas de marxismo seja a denotação geográfica presente em ambos os termos marxismo ocidental (continental europeu) e marxismo brasileiro - pois designa o traço definitivo compartilhado por ambos: a tentativa de renovação e atualização da tradição marxista, em meio a geografia desigual e combinada do capitalismo. E essa é precisamente uma das principais contribuições do marxismo do Seminário: o de seguindo a posição lukácsiana de contrariar teses e prognósticos, sem abandoar o método - submeter a teoria marxista à realidade brasileira, ampliando o escopo geral da doutrina ao agregar às suas formulações uma visão da periferia do capitalismo.

Entender a recepção brasileira do termo "marxismo ocidental" parece também pertinente para apreender os próprios limites deste conceito, seja porque ele na verdade carrega as marcas da conjuntura específica da esquerda europeia em que Anderson estava alocado quando escreveu Considerações sobre o marxismo ocidental - visível, por exemplo, na noção estreita de "prática" que ele opera ao qualificar a esterilização política dessa linhagem por ser avessa à vida partidária -, ou pela forma como a todo o momento interpreta o marxismo ocidental a partir de uma confrontação do que ele considera ser o "modelo de marxismo" - a geração de revolucionários de Lenin, Trotsky, Rosa Luxemburgo, etc. (Musse, 2012, p. 121$)^{26}$.

\footnotetext{
${ }^{26}$ Para Musse (1998, p. 15-20), "ao julgar negativamente o giro do marxismo ocidental para a filosofia", Anderson também peca ao desconsiderar "aquilo que parece ter sido a lição definitiva do livro Marxismo e filosofia, de Karl Korsch - o fato de que o marxismo sempre esteve, em qualquer época ou geração, vinculado a uma forma determinada de filosofia". Ou seja, Anderson na verdade estaria se debruçando apenas em um aspecto da obra de Marx, sintetizado em sua famosa XI Tese sobre
} 
Portanto, está por trás da conceituação de Anderson sobre o marxismo ocidental uma leitura particular da obra de Marx e da história do marxismo, que acaba deixando em segundo plano a problematização sobre a alteração histórica das condições de possibilidade da teoria marxista e a prática política efetiva. Pode-se dizer que tais particularidades da leitura de Anderson acabam sendo reforçadas com a tentativa de aplicar o conceito para pensar o caso brasileiro.

Por outro lado, a despeito dos problemas de conceituação e caracterização desta linhagem do marxismo, é inevitável a consideração sobre o impacto que os autores do marxismo ocidental tiveram no nosso país. Pois, em contrapartida a uma noção de marxismo ocidental brasileiro, existe talvez a constatação mais precisa sobre o significado do marxismo ocidental no Brasil, haja visto a recepção de pensadores como Lukács, Gramsci, Althusser, Benjamin, etc. E em relação a isso, pode-se dizer que o grupo do Seminário reforça a ideia de que o marxismo ocidental teve um papel importante na constituição do marxismo brasileiro a partir dos anos 1960. Como já pronunciado por Paulo Arantes, a leitura destes autores por parte dos marxistas do Seminário teve o "mérito de afastar do caminho de uma segunda geração de monografias clássicas sobre o Brasil a barreira nefasta do antigo dogmatismo" (Arantes, 1983, p. 5). Ou seja, é inegável como as teorias provenientes do marxismo continental europeu foram uma das bases das teses desenvolvidas a partir do Seminário, na tentativa de construir um marxismo genuinamente brasileiro, o que nos faz pensar em que medida, portanto, a recepção à brasileira do marxismo ocidental não contribuiu para que o marxismo deixasse de ser uma "ideia fora do lugar" no Brasil.

Feuerbach: "Os filósofos se limitam a interpretar o mundo, diferentemente, cabe transformá-lo". Além disso, ele de certa forma subestima o giro dos marxistas ocidentais às questões de método, como se estas fossem meras "preocupações epistemológicas", sendo que, na verdade, a "decantação dos pressupostos e das consequências metodológicas da doutrina de Marx antecede à sua aplicação - tanto à história do materialismo dialético quanto ao pensamento de Marx, ou ainda às questões do presente histórico" (Ibidem, p. 22). Ou seja, como apontava Lukács em História e Consciência de Classe, o cerne de qualquer prática revolucionária reside na compreensão apropriada da dialética, que, portanto, não é um problema menor. Ao defender isso, Lukács evidencia inclusive como estes autores, conscientes da impossibilidade de restaurar a unidade do pensamento de Marx devido as circunstâncias históricas, se apegaram ao método como forma de garantir a sobrevivência desta tradição. 
Com efeito, pode-se dizer que, antes de um "capítulo" nacional do desenvolvimento do marxismo ocidental, o que tivemos foi uma recepção brasileira dessa tradição, incorporada à luz das nossas próprias questões. Nesse sentido, o marxismo do Seminário nada mais foi do que um capítulo brasileiro dentro do esforço mundial de atualização do marxismo, do qual o marxismo ocidental também faz parte.

\section{Referências bibliográficas}

ALAMBERT, F. 1998. "Lugar da dialética, dialética do lugar - três notas sobre filiações, fidelidades e afinidades na formação intelectual de Roberto Schwarz". Em: Loureiro, I. e Musse, R. (orgs.) Capítulos do marxismo ocidental. São Paulo: Ed. Unesp.

ANDERSON, P. 2004. Considerações sobre o marxismo ocidental/Nas trilhas do materialismo histórico. São Paulo: Boitempo.

ARANTES, P. 1983. "Um capítulo brasileiro do marxismo ocidental - reconstruindo a dialética com Ruy Fausto". Folhetim, Folha de São Paulo, 19 de junho de 1983.

- 1996. Fio da meada: uma conversa e quatro entrevistas sobre filosofia e vida nacional. Rio de Janeiro: Paz e Terra.

. 1994. "Falsa consciência como força produtiva". Em: Arantes, P. Um departamento francês de ultramar: estudos sobre a formação da cultura filosófica uspiana. Rio de Janeiro: Paz e Terra.

CARDOSO, F. H. 1977. Capitalismo e escravidão no Brasil meridional. Rio de Janeiro: Paz e Terra.

1972. Empresário industrial e desenvolvimento econômico no Brasil. São Paulo: Difel.

HARVEY, D. 2003. "Marx redux". Em: ANTONIO, R. (ed.). Marx and modernity: key readings and commentary. Oxford: Blackwell Publishing.

HOBSBAWM, E. 1998. (org.) História do marxismo. Vol. 11 - O marxismo hoje (primeira parte). Rio de Janeiro: Paz e Terra.

JAMESON, F. 1985. Marxismo e forma. São Paulo: Hucitec.

. 1991. "Periodizando os anos 1960". Em: Hollanda, H. B. (org.). Pós-modernismo e política. Rio de Janeiro: Rocco.

1992. O inconsciente político. São Paulo: Ática.

Unesp.

1996. O marxismo tardio: Adorno ou a persistência da dialética. São Paulo: Ed. 
KONDER, L. 2010. "Os marxistas brasileiros: primeiros militantes”. Em: Konder, L. Em torno de Marx. São Paulo: Boitempo.

KORSCH, K. 2008. Marxismo e filosofia. Rio de Janeiro: Ed. UFRJ.

LAHUERTA, M. 2005. "Em busca da formação social brasileira: marxismo e vida acadêmica". Perspectivas, São Paulo, 28: 157-186.

LUKÁCS, G. 2012. História e consciência de classe: estudos sobre a dialética marxista. São Paulo: Martins Fontes, 2012.

MUSSE, R. 1998. "Teoria e Prática". Em: Loureiro, I. M. \& Musse, R. (orgs.). Capítulos do Marxismo Ocidental. São Paulo: UNESP.

2012. "Algumas observações sobre a historiografia do marxismo ocidental". Em: Dialética e teoria crítica: ensaios sobre Lukács, Korsch, Adorno e a historiografia do marxismo. Universidade de São Paulo, São Paulo. 409-425.

. 2015. "As aventuras do marxismo no Brasil". Cadernos $C R H$, Salvador, v. 28, n. 74, p.

NOVAIS, F. 1983. Portugal e Brasil na crise do Antigo Sistema Colonial. São Paulo: Hucitec.

OLIVEIRA, F. 2003. Crítica à razão dualista/O ornitorrinco. São Paulo: Boitempo.

MERLEAU-PONTY, M. 2006. As aventuras da dialética. São Paulo: Martins Fontes.

QUERIDO, F. M. 2018. Um capítulo da sociologia crítica paulista: a trajetória do Cenedic (19952015), mimeo, 2018, 40p.

RICUPERO, B. 2000. “Existe um pensamento marxista latino-americano?". Em: Caio Prado e a nacionalização do marxismo no Brasil. São Paulo, Editora 34. 73: 59-59.

2008. "Da formação à forma. Ainda as 'ideias fora do lugar". Lua Nova, São Paulo,

SADER, E. 2004. "O marxismo ocidental no Brasil". Em: Anderson, P. Considerações sobre o marxismo ocidental/Nas trilhas do materialismo histórico. São Paulo: Boitempo.

2005. "Nós que amávamos tanto o capital - fragmentos para a história de uma geração". Sociologias, ano 7, n. 14, jul/dez, pp. 150-177.

SCHWARZ, R. 1999a. "Um seminário de Marx". Em: Sequências brasileiras. São Paulo: Companhia das Letras.

. 1999b. "Fim de século". In: Sequências brasileiras. São Paulo: Companhia das Letras.

. 2014a. "As ideias fora do lugar". Em: As ideias fora do lugar: ensaios selecionados. São Paulo: Penguin Classics/Companhia das Letras. 
2014b. "Nacional por subtração". Em: As ideias fora do lugar: ensaios selecionados. São Paulo: Penguin Classics/Companhia das Letras.

THERBORN, G. 2012. "O marxismo do século XX e a dialética da modernidade". Em: Do marxismo ao pós-marxismo? São Paulo: Boitempo.

Tramitação do artigo na revista Submetido: 26/02/2019

Revisões requeridas: 11/03/2019

Versão revista: 11/03/2019

Aceito: 22/03/2019 